Document downloaded from:

http://hdl.handle.net/10251/121856

This paper must be cited as:

Grirrane, A.; Alvarez-González, E.; García Gómez, H.; Corma Canós, A. (2018). Double A(3)-Coupling of Primary Amines Catalysed by Gold Complexes. Chemistry - A European Journal. 24(61):16356-16367. https://doi.org/10.1002/chem.201803020

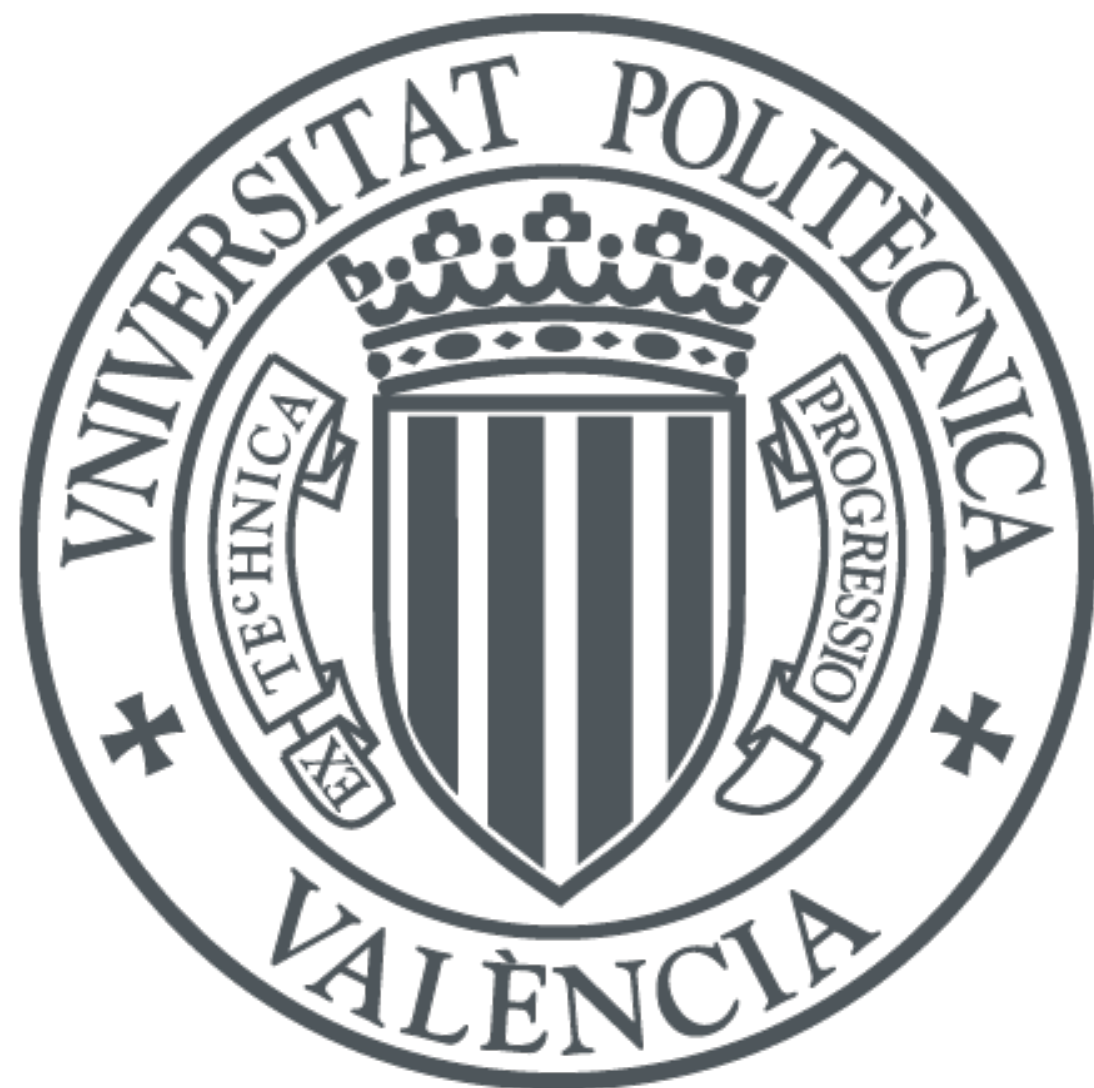

The final publication is available at

http://doi.org/10.1002/chem.201803020

Copyright John Wiley \& Sons

Additional Information

This is the peer reviewed version of the following article:Grirrane, Abdessamad, AlvarezGonzález, Eleuterio, García Gómez, Hermenegildo, Corma Canós, Avelino. (2018). Double A(3)-Coupling of Primary Amines Catalysed by Gold Complexes.Chemistry - A European Journal, 24, 61, 16356-16367. DOI: 10.1002/chem.201803020, which has been published in final form athttp://doi.org/10.1002/chem.201803020. This article may be used for noncommercial purposes in accordance with Wiley Terms and Cond 


\title{
Double $A^{3}$-coupling of primary amines catalysed by gold complexes
}

\author{
Abdessamad Grirrane ${ }^{1}$, Eleuterio Álvarez ${ }^{2}$, Hermenegildo Garcia ${ }^{1}$ and Avelino Corma ${ }^{1}$ \\ ${ }^{1}$ Instituto Universitario de Tecnología Química CSIC-UPV, Universitat Politécnica de \\ Valencia, Av. De los Naranjos s/n, 46022 Valencia (Spain) and ${ }^{2}$ Instituto de \\ Investigaciones Químicas CSIC-US, Departamento de Química Inorgánica, Av. \\ Américo Vespucio 49, 41092 Sevilla (Spain).
}

Abstract: A novel family of dipropargylamine has been synthesized in one pot through a double catalytic $\mathrm{A}^{3}$ - coupling of five component. Cationic $[\mathrm{Au}(\mathrm{I})-\mathrm{L}]\left[\mathrm{SbF}_{6}\right]$ complexes $(\mathrm{L}=$ JohnPhos $)$ are extremely active to promote this catalytic double $\mathrm{A}^{3}$ - coupling of primary amine (aliphatic or aromatic), formaldehyde and trimethylsilylacetylene. Several reactions of LAu-amine complexes with organic reagents were studied and followed by NMR and HRESI-MS spectroscopies, providing information about the reaction mechanism. Specifically the role of the $\pi$-gold(I) acetylide complexes as active catalyst species was firmly confirmed. Most of the intermediates of this five-component coupling were identified by GC-MS spectroscopy lending support to mechanistic proposal .In some cases, cationic amine-gold(I)-L complexes corresponding to the activated reagent or intermediate have been isolated, characterized by single-crystal X-ray diffraction, measured their spectroscopic properties and their catalytic activity evaluated. Protic solvents influence the course of the reaction by effecting the double deprotection of dipropargylamines, providing a convenient route to double-deprotected silyl moieties dipropargylamines. When $\mathrm{NaOH}$ is present in the reaction media, formation of cationic acetylide-dipropargylamine gold(I) and neutral hydroxide $\mathrm{LAuOH}$ complexes, respectively, as high and less active intermediate catalyst forms occurs.

Several multicomponent reactions (MCRs) for the preparation of propargylamines, ${ }^{[1]}$ from amines, aldehydes, and terminal alkynes ( $\mathrm{A}^{3}$-coupling reaction) have been recently published. However, only a few of them have reported the one-pot double $\mathrm{A}^{3}$-coupling of five components. ${ }^{[11,2]}$ Moreover, double $\mathrm{A}^{3}$-coupling of five component of more challenging primary amines as substrates has been even more rarely reported. ${ }^{[3]}$ In one of the precedents works, ${ }^{[4]}$ this reaction was catalysed by a mixture of $\mathrm{RuCl}_{3} / \mathrm{CuBr}$ at a loading ranging between 21 to $25 \mathrm{~mol} \%$. In other published article, ${ }^{[3 \mathrm{~b}]}$ this five 
component coupling was catalysed by $[\mathrm{IrCl}(\operatorname{cod})]_{2}(10 \mathrm{~mol} \%)$ in dioxane at $75{ }^{\circ} \mathrm{C}$ or cyclopentyl ether at $100{ }^{\circ} \mathrm{C}$ as solvents. In another recent study on this catalytic multicomponent coupling stoichiometric amounts of $\mathrm{Na}_{2} \mathrm{CO}_{3}$ as additive together with 20 $\%$ of $\mathrm{CuBr}$ as catalyst was required. ${ }^{[5]}$ In view of the current state of the art, it would be desirable to expand this five component coupling to primary amines for the preparation of new dipropargyl amines using more efficient and recoverable catalyst in lower molar ratios.

The known activity of homogeneous gold catalysts ${ }^{[6]}$ with $[\mathrm{L}-\mathrm{Au}(\mathrm{I})][\mathrm{A}](\mathrm{L}=$ phosphine and $\mathrm{A}=$ counterion) structure for a recently reported five component, double $\mathrm{A}^{3}$ coupling reaction to prepare tremorine and gemini surfactants ${ }^{[2 \mathrm{~d}]}$ makes it a good candidate catalyst to be tested also for primary amines. In this context herein, an efficient homogeneous $\mathrm{Au}(\mathrm{I})$ catalyst for the one pot, five components, double $\mathrm{A}^{3}$-coupling preparation of new dipropargylamines using primary amines (either aromatic or aliphatic), ethynyltrimethylsilane (TMS-acetylene) and formaldehyde is described. Due to the excellent yield of the double coupling products, the possibility to convert them into their corresponding free terminal alkynes was also envisioned. Furthermore, Some diacetylene-dipropargyl amines adducts of the $\mathrm{Au}(\mathrm{I})$ catalyst have been isolated and their corresponding monoacetylene dipropargyl amines intermediates identified by GC-MS.

The method reported here consists in the five-components coupling of a primary amine, ethynyltrimethylsilane (TMS-acetylene) and formaldehyde in a 1:2.5:3.5 ratio catalysed by cationic $[\mathrm{LAu}(\mathrm{NCMe})]\left[\mathrm{SbF}_{6}\right]$ (1) [Table 1]. Initial studies began using aniline (2), TMS-acetylene (3) and aqueous (37\%) formaldehyde (4) as reagents [Table 1, scheme (Top)]. Formation of N-phenylmethanimine (5), N-(3-(trimethylsilyl)prop-2-yn-1yl)aniline (6), N-methylene-N-(3-(trimethylsilyl)prop-2-yn-1-yl)benzenaminium (7) and N,N-bis(3-(trimethylsilyl)prop-2-yn-1-yl)aniline (8) [Table 1, Scheme] either as intermediates or as final product reaction, respectively, was observed. Compound (8) is formed in high yield and selectivity. One important conclusion from Table 1 (entries 24) is that the cationic $\mathrm{Au}^{\mathrm{I}}$ complex (1) is more active in $\mathrm{CH}_{2} \mathrm{Cl}_{2}$ as solvent than in ethanol or toluene. This higher activity of $\mathbf{1}$ in $\mathrm{CH}_{2} \mathrm{Cl}_{2}$ can be explained by its higher solubility in this solvent and the lack of desilylation of TMS-protected alkynes 6 and 7, formed as reaction intermediates. Controls in the absence of any catalyst do not allow the detection of any product (Table 1, entry 1). Compound 8 was characterized by NMR spectroscopy and GC-MS (see the experimental section and Figs. S1-S5 in Supporting Information). 
${ }^{1} \mathrm{H},{ }^{13} \mathrm{C}$, DEPT and ${ }^{29} \mathrm{Si}$ NMR spectra in $\mathrm{CD}_{2} \mathrm{Cl}_{2}$ provided evidence that the starting aniline (2) and the intermediate compounds 5, 6 and 7 are completely converted into dipropargyl amine 8 (see Fig. S1-S4 in the SI). GC-MS data of 8 shows a peak at $313.3 \mathrm{Da}$ in agreement with the expected molecular formula $\left(\mathrm{C}_{18} \mathrm{H}_{27} \mathrm{~N}_{2} \mathrm{Si}_{2}\right)$ (see Fig. S5 in the SI). The intermediate compound $5\left(\mathrm{C}_{7} \mathrm{H}_{7} \mathrm{~N}\right)$ formed at very early stages was characterized by its GC-MS that shows a peak at 105.2 Da (see Fig. S6 in the SI). The intermediate compounds $6\left(\mathrm{C}_{12} \mathrm{H}_{17} \mathrm{NSi}\right)$ and $7\left(\mathrm{C}_{13} \mathrm{H}_{18} \mathrm{NSi}^{+}\right)$are proposed also based on GC-MS of the kinetic study of this reaction (Table 1, entry 2) that shows peaks at 203.3 and 217.3 Da, respectively, in agreement with their expected molecular formulae (see Fig. S7 for 6 and Fig. S8 for 7 in the SI). The solid catalyst can be recovered from the reaction mixture when $\mathrm{CH}_{2} \mathrm{Cl}_{2}$ is used as solvent by adding cold $n$-hexane, filtering the solid precipitate and drying under vacuum at RT [Table 1 (entries 2)]. Then, the recovered catalyst can be reused several times without observing loss of activity and selectivity [Table 1 (entries 5$6)]$.

Table 1. One pot, double $\mathrm{A}^{3}$ - coupling of aniline (2), TMS-acetylene (3), and formaldehyde (4) with complex of $A u(I) 1$ as catalysts $(5 \mathrm{~mol} \%)^{[a]}$

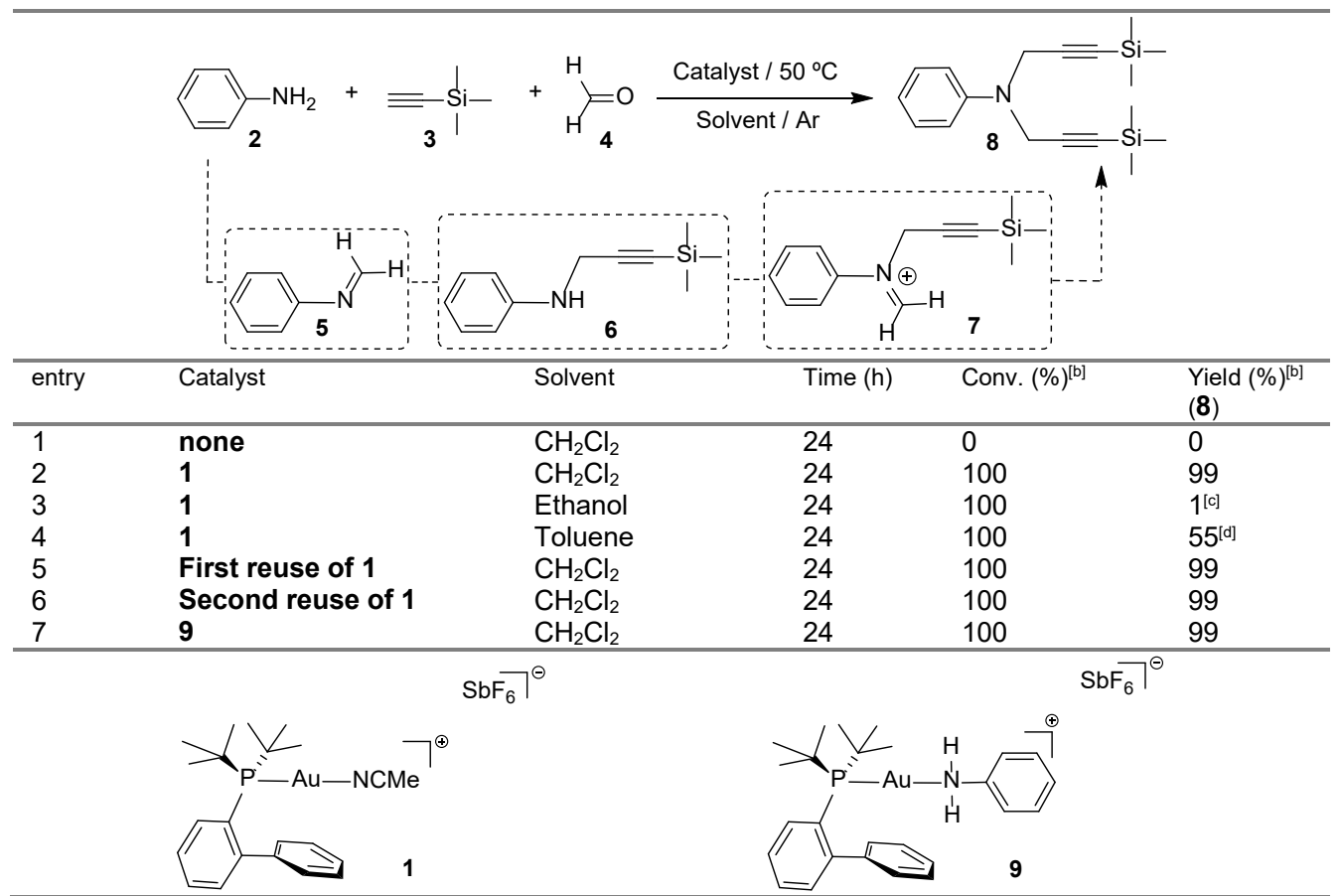

[a] Reactions were carried out using $0.25 \mathrm{mmol}$ of aniline, $0.7 \mathrm{mmol}$ of TMS-acetylene, and $1 \mathrm{mmol}$ of aqueous formaldehyde and $1.5 \mathrm{ml}$ of solvent. [b] conv. of $\mathbf{2}$ and yield of $\mathbf{8}(\%)$ were determined by ${ }^{1} \mathrm{H}$ NMR spectroscopy and GC of the crude reaction mixture. [c] $20 \%$ of $5(105 \mathrm{Da})$ was detected together with $41 \%$ of its corresponding dimer (209 Da) [see Fig. S6 in the SI] and $37 \%$ of 7. [d] $44 \%$ of intermediates 5, 6 and 7 mixture was present. 
Under the optimal conditions, catalyst evaluation was extended to the cationic complex $[\mathrm{LAu}$ (aniline) $]\left[\mathrm{SbF}_{6}\right](\mathbf{9})^{[7]}$ (Table 1, bottom). Also, in this case, compound 8 was obtained in good yield (Table 1, entry 7). It was observed that the activity of the catalysts $\mathbf{1}$ and $\mathbf{9}$ is similar [Table 1 (entries 2 and 7). This similar catalytic activity of complexes 1 and 9 can be explained by the fast formation of 9 as one of the intermediate gold complexes when the reaction is promoted by addition of the gold complex $\mathbf{1}$.

To expand the scope of this catalytic process, ethynyltrimethylsilane (3) and aqueous formaldehyde (4) were reacted under optimal conditions with aromatic primary amines $(\mathbf{1 0}, \mathbf{1 5}, \mathbf{2 0}, \mathbf{2 5}$ and 30) having electron donor or acceptor substituents (see Table 2). The expected condensation products $(\mathbf{1 1}, \mathbf{1 6}, \mathbf{2 1}, \mathbf{2 6}$ and 31) formed at earlier stage of the reactions, followed by mono-TMS-protected alkynes $(12,17,22,27$ and 32) and cationic mono-TMS-protected alkynes $(\mathbf{1 3}, \mathbf{1 8}, \mathbf{2 3}, \mathbf{2 8}$ and 33) as, second and third reaction intermediates, analogous to those indicated in the scheme of Table 1, were observed. All these intermediates were characterized by GC-MS during the kinetic studies of these reactions, showing molecular peaks in agreement with the expected molecular formulae (see the experimental section and Figs. S9-S23 in SI). GC-MS data of the imines 11 $\left(\mathrm{C}_{7} \mathrm{H}_{6} \mathrm{IN}\right), 16\left(\mathrm{C}_{7} \mathrm{H}_{6} \mathrm{BrN}\right), 21\left(\mathrm{C}_{8} \mathrm{H}_{9} \mathrm{NO}\right), 26\left(\mathrm{C}_{9} \mathrm{H}_{11} \mathrm{~N}\right)$ and $31\left(\mathrm{C}_{9} \mathrm{H}_{9} \mathrm{~N}\right)$ (see Table 2$)$ show peaks at 231.1, 183.1, 135.2, 133.3 and 131.2 Da, respectively, in agreement with their expected molecular formulae (see Figs. S9, S10, S11, S12 and S13 in the SI). Similarly, the products of the mono $\mathrm{A}^{3}$-coupling $12\left(\mathrm{C}_{12} \mathrm{H}_{16} \mathrm{INSi}\right), 17\left(\mathrm{C}_{12} \mathrm{H}_{16} \mathrm{BrNSi}\right), 22$ $\left(\mathrm{C}_{13} \mathrm{H}_{19} \mathrm{NOSi}\right), 27\left(\mathrm{C}_{14} \mathrm{H}_{21} \mathrm{NSi}\right)$ and $32\left(\mathrm{C}_{14} \mathrm{H}_{19} \mathrm{NSi}\right)$ were also characterized by GC-MS by recording peaks at 329.1,281.1,233.2,231.2 and 229.2 Da, respectively, in agreement with their expected molecular formulae (see Figs. S14, S15, S16, S17 and S18 in the SI). The cationic mono $\mathrm{A}^{3}$-coupling iminium ions $13\left(\mathrm{C}_{13} \mathrm{H}_{17} \mathrm{INSi}^{+}\right), \mathbf{1 8}\left(\mathrm{C}_{13} \mathrm{H}_{17} \mathrm{BrNSi}^{+}\right), 23$ $\left(\mathrm{C}_{14} \mathrm{H}_{20} \mathrm{NOSi}^{+}\right), 28\left(\mathrm{C}_{15} \mathrm{H}_{22} \mathrm{NSi}^{+}\right)$and $33\left(\mathrm{C}_{15} \mathrm{H}_{20} \mathrm{NSi}^{+}\right)$(see Table 2) were also characterized by GC-MS, by observing peaks at 343.1, 294.1, 247.2, 245.3 and 243.2 Da, respectively, in agreement with their expected molecular formulae (see Figs. S19, S20, $\mathrm{S} 21, \mathrm{~S} 22$ and S23 in the SI). 


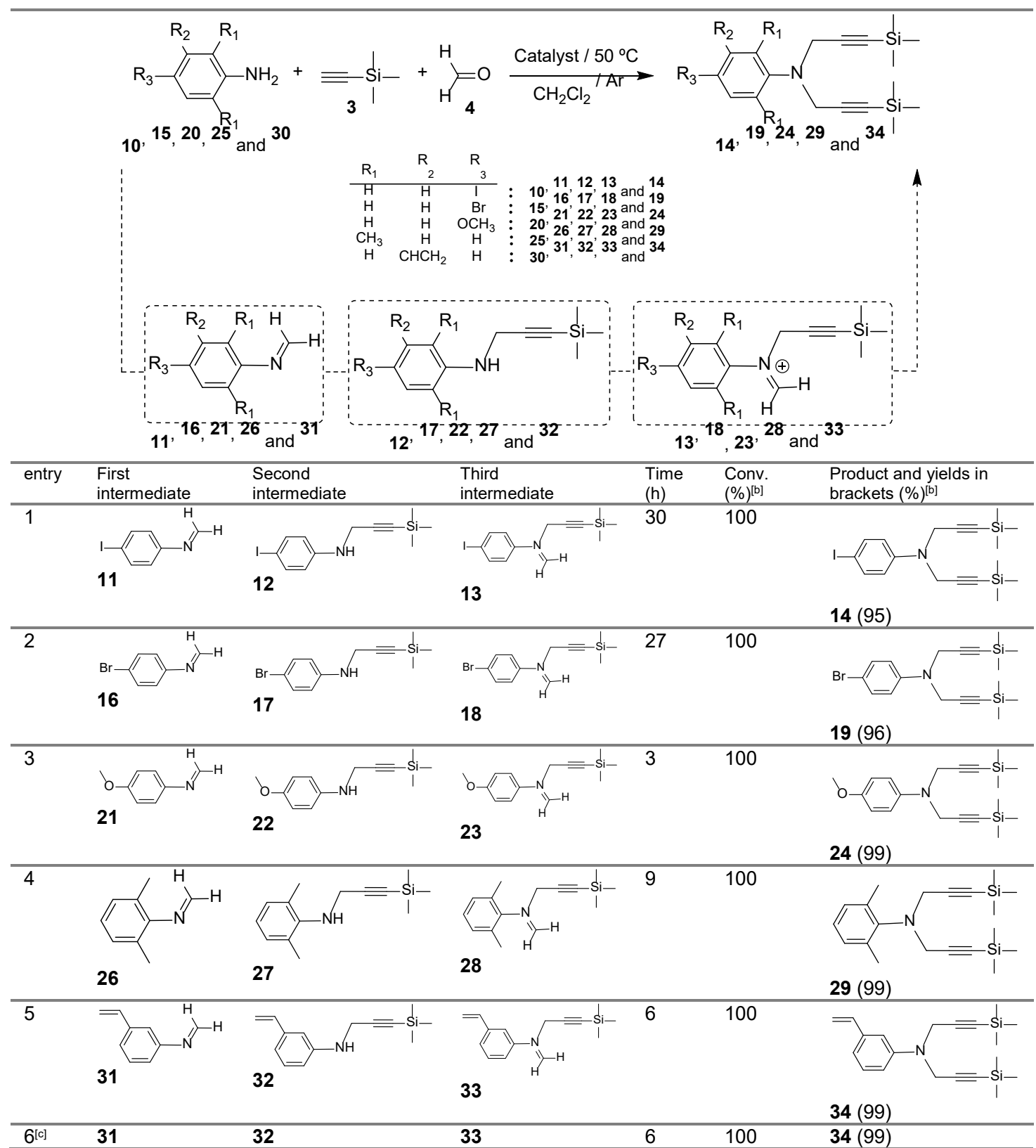

[a] Reactions were carried out using $0.25 \mathrm{mmol}$ of amine, 0.7 of TMS-acetylene and $1 \mathrm{mmol}$ of aqueous formaldehyde and $1.5 \mathrm{ml}$ of $\mathrm{CH}_{2} \mathrm{Cl}_{2}$. [b] conv. of anilines $10,15,20,25,30$ and yield of final products 14, 19, 24, 29, 34 (\%) were determined by ${ }^{1} \mathrm{H}$ NMR spectroscopy and GC of the crude reaction mixture. [c] Cationic complex [LAu(3vinylaniline)][SbF 6$](35)$ was used as catalyst.

The final wanted disilylated-dipropargylamines (see Table 2) were isolated and characterized by ${ }^{1} \mathrm{H},{ }^{13} \mathrm{C}$, DEPT and ${ }^{29} \mathrm{Si}$ NMR spectroscopy, all of them providing evidence that, under the condition given in Table 2, starting primary amines 10, 15, 20, 25, 30 and their corresponding intermediates were completely converted into final propargylamines 14, 19, 24, 29 and 34, respectively (see Figs. S24-S27 for 14, S29-S32 for 19, S34-S37 for $\mathbf{2 4}, \mathrm{S} 39-\mathrm{S} 42$ for $\mathbf{2 9}$ and S44-S47 for $\mathbf{3 4}$ in the SI). GC-MS data obtained dissolving $14\left(\mathrm{C}_{18} \mathrm{H}_{26} \mathrm{INSi}_{2}\right), \quad 19\left(\mathrm{C}_{18} \mathrm{H}_{26} \mathrm{BrNSi}_{2}\right), 24\left(\mathrm{C}_{19} \mathrm{H}_{29} \mathrm{NOSi}_{2}\right), 29$ 
$\left(\mathrm{C}_{20} \mathrm{H}_{31} \mathrm{NSi}_{2}\right)$ and $34\left(\mathrm{C}_{20} \mathrm{H}_{29} \mathrm{NSi}_{2}\right)$ in $\mathrm{CH}_{2} \mathrm{Cl}_{2}$ show peaks at $439.2,391.2,343.3,341.3$ and 339.3 Da, respectively, in agreement with the expected molecular formulae (see Figs. S28, S33, S38, S43 and S48, respectively, in the SI). Regarding the influence of the substituents, the presence of electron donor substituents at the para-position on aromatic ring [Table 2 (entries 1-3)], increases the yield at short reaction time (3 h) compared to electron withdrawing ones[Table 2 (entries 1 and 2)]. It was also observed that methyl groups at the ortho position of the aromatic amine [Table 2 (entry 4)] improves the yield at shorter reaction time $(9 \mathrm{~h})$ compared to hydrogen [Table 1 (entry 1$)$ ] in agreement with the electron donor behavior of methyl group and also indicating that the coupling is not sensitive to steric effects. Also the presence of electron donor vinyl group as meta substituent of the aromatic amine (30) increases the yield at shorter reaction time (6 h) [Table 2 (entry 5)]. Product selectivity to compound $\mathbf{3 4}$ in the case of substrate $\mathbf{3 0}$ also indicates that undesirable side reactions at to the alkene functional group does not occur.

Encouraged by this remarkable catalytic results of the 3-vinylaniline (30) forming dipropargylamine 34 in high yield and excellent selectivity [Table 2 (entry 5)], an attempt to identify the possible intermediate between cationic [LAu(NCMe)][SbF 6$](\mathbf{1})$ and 3vinylaniline (30) was made. Aimed at this purpose, the reaction of gold(I) complex 1 with

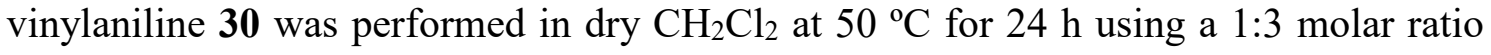
(Scheme 1). The resulting pale yellow solution was diluted with additional $\mathrm{CH}_{2} \mathrm{Cl}_{2}$, followed by dilution with toluene. Upon standing three days this mixture at RT, formation in $97 \%$ yield of colourless crystals assigned, to the air-stable cationic gold(I) $\left[\mathrm{LAu}\left(\mathrm{H}_{2} \mathrm{~N}-\right.\right.$ $\mathrm{Ph}$-vinyl)][SbF 6$]$ (35) was observed. Complex 35 was fully characterized by analytical and spectroscopic data (see the experimental Section, Table S1 and Figures S49-S54 in the SI].

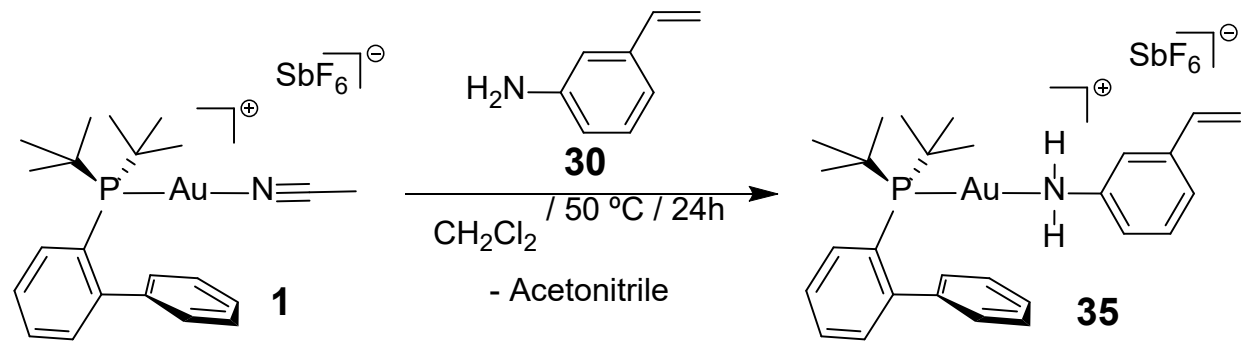

Scheme 1. Synthesis of the cationic gold (I) complex 35 . 
${ }^{1} \mathrm{H},{ }^{13} \mathrm{C}$, DEPT and ${ }^{31} \mathrm{P}$ NMR spectra in $\mathrm{CD}_{2} \mathrm{Cl}_{2}$ provided evidence that under the reaction conditions the starting cationic gold(I) complex $\mathbf{1}$ is completely converted to the cationic gold(I) complex 35 with release of an acetonitrile ligand (see Figures S49-S52 in the SI). Thus, ${ }^{31} \mathrm{P}$ NMR spectrum showed the appearance of a new peak at $\delta=59.32 \mathrm{ppm}$ due to new complex 35 (see Figures S52 in the SI). This peak in the ${ }^{31} \mathrm{P}$ NMR spectrum is different from that of the original gold(I) complex 1 (57.49 ppm). Similarly to ${ }^{31} \mathrm{P}$ NMR spectroscopy, the ${ }^{1} \mathrm{H}$ NMR spectrum also showed the appearance of new signals of methyl groups for gold(I) complex 35 at 1.34/1.29 instead of 1.38/1.33 ppm corresponding to the initial gold(I) complex 1 (see Figures S49 in the SI). The presence of unreacted vinyl group in the gold(I) complex 35 was confirmed by ${ }^{1} \mathrm{H},{ }^{13} \mathrm{C}$ and DEPT spectra (see Figures $\mathrm{S} 49-\mathrm{S} 51$ in the SI). The ${ }^{1} \mathrm{H}$ NMR signals corresponding to the vinyl group appeared at 6.70-6.55 (dd, $\left.1 \mathrm{H}, \mathrm{H}_{2} \mathrm{C}=\mathrm{CH}-, J=17.58,10.90 \mathrm{~Hz}\right), 5.79-5.66(\mathrm{~d}, 1 \mathrm{H}, \mathrm{HHC}=\mathrm{CH}-, J=$ $17.58 \mathrm{~Hz})$ and $5.32-5.20(\mathrm{dd}, 1 \mathrm{H}, \mathrm{HHC}=\mathrm{CH}-, J=10.90 \mathrm{~Hz})$ (see Figures $\mathrm{S} 49$ in the $\mathrm{SI}$ ).

ESI-MS of the solution obtained by dissolving cationic [ $\mathrm{LAu}\left(\mathrm{H}_{2} \mathrm{~N}-\mathrm{Ph}\right.$-vinyl $\left.)\right]\left[\mathrm{SbF}_{6}\right] 35$ complex in $\mathrm{CH}_{2} \mathrm{Cl}_{2}$ showed an intense positive MS peak at $614.3 \mathrm{Da}$ (see Fig. S53 in the SI) that is attributable to the cationic $\left[\mathrm{C}_{28} \mathrm{H}_{36} \mathrm{AuF} \mathrm{F}_{6} \mathrm{NPSb}(\mathbf{3 5})-\mathrm{SbF}_{6}\right]^{+}$species, the experimental peak cluster showing a good agreement with the simulated isotopic distribution for the molecular formula $\left[\mathrm{C}_{28} \mathrm{H}_{36} \mathrm{AuNP}\right]$ (See Fig. S53 in the SI). On the other hand, negative MS peaks were recorded at 234.7 and 236.6 Da corresponding to the two isotopes ${ }^{121} \mathrm{Sb}$ and ${ }^{123} \mathrm{Sb}$ of $\left[\mathrm{SbF}_{6}\right]^{-}$counter anion (See Fig. S53 in the SI), also in good accordance with the simulated isotopic distribution for the molecular formula $\left[\mathrm{SbF}_{6}\right]$ (See Fig. S53 in the SI).

The structure of cationic gold(I) complex 35 in the solid state was confirmed by singlecrystal X-ray diffraction. Ortep of this new cationic $\left[\mathrm{LAu}\left(\mathrm{H}_{2} \mathrm{~N}-\mathrm{Ph}\right.\right.$-vinyl)][SbF 6$] 35$ complex is shown in Figure 1 (For X-ray data, ortep view and crystal packing details see Table S1 and Fig. S54 in the SI). Of note is that this structure 35 is closely related to the our previously reported cationic [LAu(aniline)][SbF6] (10) complex..$^{[7]}$

Selected bond lengths for Au1-N1, Au1-P1 and Au1-C15ipso that is the closest carbon atom of the distal phenyl ring for complex 35 (Table S1 and Fig. S54 in the SI) are 2.109(12), 2.250(3) and $2.978 \AA$, respectively. Very similar bond lengths to those determined here for $\mathbf{3 5}$ were found in our previous published cationic 
[LAu(aniline)][SbF 6$]$ (10) complex, with Au-N1, Au-P1 and Au1-C13 ${ }_{\text {ipso }}$ distances of $2.118(8), 2.250(2)$ and $2.985 \AA$, respectively.

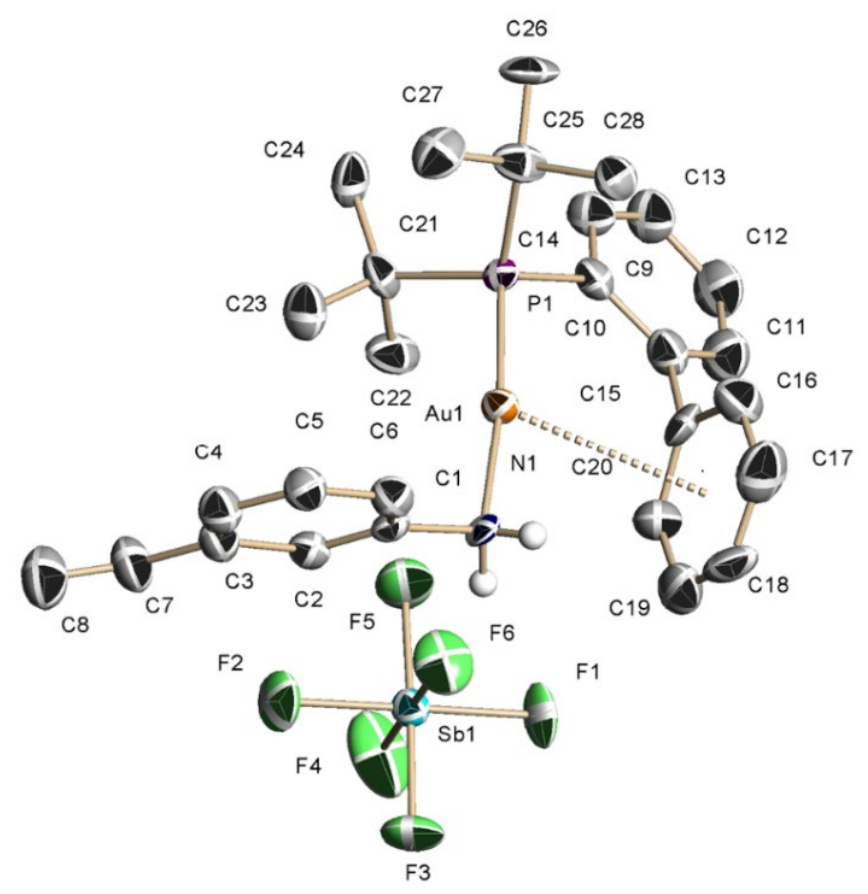

Figure1. ORTEP of cationic gold (I) complex 35; hydrogen atoms bound to carbon atoms are omitted for clarity, and thermal ellipsoids are set at $30 \%$ probability level (a singlecrystal X-ray crystal structure analysis data and crystal packing details are given in Table S1 and Fig.S54in the SI).

The catalytic activity of cationic $\left[\mathrm{LAu}\left(\mathrm{H}_{2} \mathrm{~N}-\mathrm{Ph}\right.\right.$-vinyl $\left.)\right]\left[\mathrm{SbF}_{6}\right]$ complex 35 was also tested for the five-component coupling, observing the formation of N,N-bis(3(trimethylsilyl)prop-2-yn-1-yl)-3-vinylaniline (34) with high yield and excellent selectivity [Table 2 (entry 6)]. This catalytic activity of $\mathbf{3 5}$ is similar to that obtained for cationic $[\mathrm{LAu}(\mathrm{NCMe})]\left[\mathrm{SbF}_{6}\right]$ (1) complex as catalyst [Table 2 (entry 5)].

It is known that the reaction rates and yields of $\mathrm{A}^{3}$ coupling are highly dependent on the nature of the primary amines used as reagent. To determine the scope of double $\mathrm{A}^{3}$ coupling ethynyltrimethylsilane (3) and aqueous formaldehyde (4) were reacted under optimal conditions with benzyl and other aliphatic primary amine. 3,4(Methylenedioxy)benzylamine (36), phenethylamine (41), isobutylamine (46) and $n$ butylamine (51) were screened as substrates using cationic $\mathrm{Au}(\mathrm{I})$ complex $\mathbf{1}$ as catalyst (see Table 3). The imine condensation products $(\mathbf{3 7}, \mathbf{4 2}, 47$ and 52), mono-TMS-protected 
alkynes (38, 43, 48 and 53) and cationic mono-TMS-protected alkyne iminium (39, 44, 49 and 54), were observed, as first, second and third reaction intermediates [Table 3, Scheme (Top)]. All these intermediates were detected by GC-MS during the kinetic studies of these reactions, showing peaks in agreement with the expected molecular formulae (see the experimental section and Figs. S55-S66 in SI). GC-MS data of imines $37\left(\mathrm{C}_{9} \mathrm{H}_{9} \mathrm{NO}_{2}\right), 42\left(\mathrm{C}_{9} \mathrm{H}_{11} \mathrm{~N}\right), 47\left(\mathrm{C}_{5} \mathrm{H}_{11} \mathrm{~N}\right)$ and $52\left(\mathrm{C}_{5} \mathrm{H}_{11} \mathrm{~N}\right)$ (see Table 3) exhibit peaks at 163.2, 133.2, 85.2 and 85.2 Da, respectively (see Figs. S55, S65, S57 and S58 in the SI). The products of mono $\mathrm{A}^{3}$ coupling $38\left(\mathrm{C}_{14} \mathrm{H}_{19} \mathrm{NO}_{2} \mathrm{Si}\right), \mathbf{4 3}\left(\mathrm{C}_{14} \mathrm{H}_{21} \mathrm{NSi}\right), 48\left(\mathrm{C}_{10} \mathrm{H}_{21} \mathrm{NSi}\right)$ and $53\left(\mathrm{C}_{10} \mathrm{H}_{21} \mathrm{NSi}\right)$ showed GC-MS peaks at 261.2, 231.3, 183.2 and $183.2 \mathrm{Da}$, respectively (see Figs. S59, S60, S61 and S62 in the SI). Finally, GC-MS data of the iminium intermediates $39\left(\mathrm{C}_{15} \mathrm{H}_{20} \mathrm{NO}_{2} \mathrm{Si}^{+}\right), 44\left(\mathrm{C}_{15} \mathrm{H}_{22} \mathrm{NSi}^{+}\right), 49\left(\mathrm{C}_{11} \mathrm{H}_{22} \mathrm{NSi}^{+}\right)$and 54 $\left(\mathrm{C}_{11} \mathrm{H}_{22} \mathrm{NSi}^{+}\right.$) (see Table 3) showed peaks at 274.2, 244.2, 196.3 and $196.2 \mathrm{Da}$, respectively, in agreement with their expected molecular formulae (see Figs. S63, S64, S65 and S66 in the SI).

Table 3. One pot, five components, double $\mathrm{A}^{3}$ - coupling of TMS-acetylene, primary amines, and aqueous formaldehyde promoted by $\mathrm{Au}(\mathrm{I})$ complex 1 as catalysts $(5 \mathrm{~mol} \%){ }^{[\mathrm{a}]}$

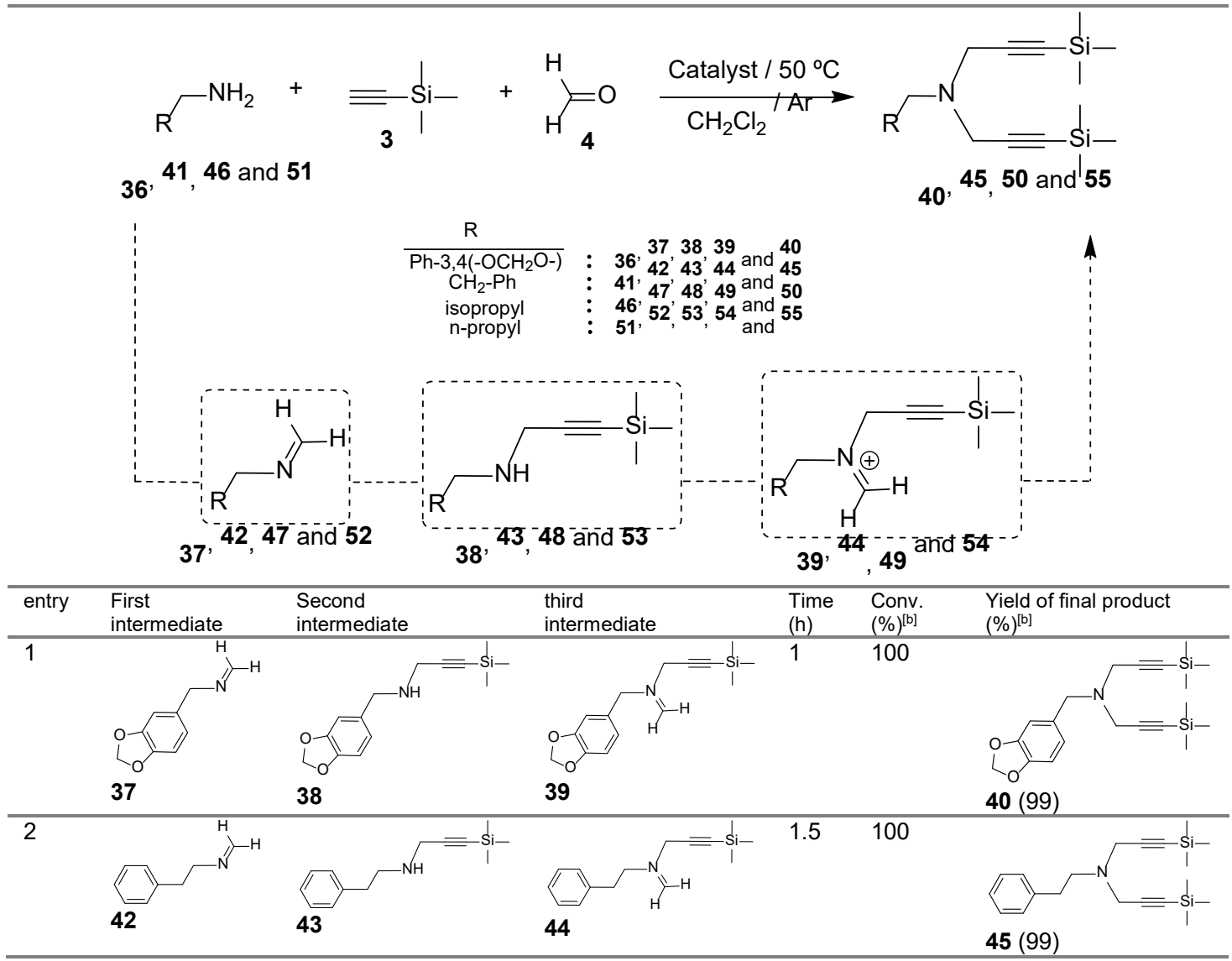




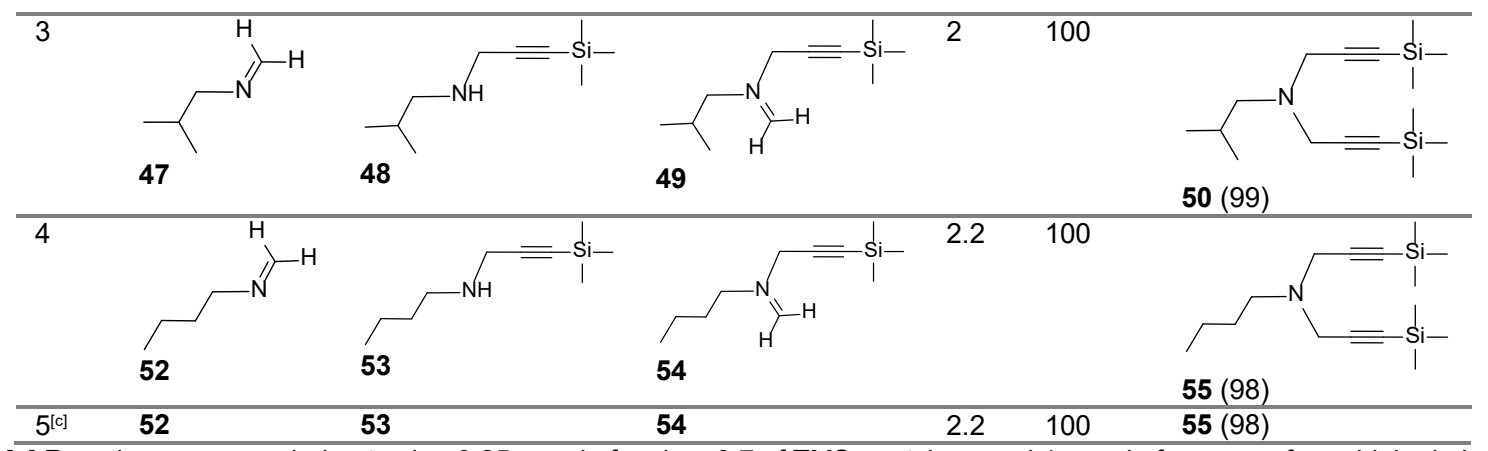

[a] Reactions were carried out using $0.25 \mathrm{mmol}$ of amine, 0.7 of TMS-acetylene and $1 \mathrm{mmol}$ of aqueous formaldehyde in $1.5 \mathrm{ml}$ of $\mathrm{CH}_{2} \mathrm{Cl}_{2}$. [b] conv. of amines $36,41,46,51$ and yield of final products $40,45,50,55(\%)$ were determined by ${ }^{1} \mathrm{H}$ NMR spectroscopy and GC of the crude reaction mixture. [c] Cationic complex [LAu( $n$-Butylamine][SbF 6 (56) was used as catalyst.

The wanted dipropargylamines $\mathrm{N}-($ benzo[d][1,3]dioxol-5-ylmethyl)-3-(trimethylsilyl)N-(3-(trimethylsilyl)prop-2-yn-1-yl)prop-2-yn-1-amine $\quad \mathbf{( 4 0 ) , \quad \quad \quad N - p h e n e t h y l - 3 - ~}$ (trimethylsilyl)-N-(3-(trimethylsilyl)prop-2-yn-1-yl)prop-2-yn-1-amine (45), N-isobutyl3-(trimethylsilyl)-N-(3-(trimethylsilyl)prop-2-yn-1-yl)prop-2-yn-1-amine (50) and N,Nbis(3-(trimethylsilyl)prop-2-yn-1-yl)butan-1-amine (55) were isolated in excellent yields (see Table 3) and characterized by ${ }^{1} \mathrm{H},{ }^{13} \mathrm{C}$, DEPT and ${ }^{29} \mathrm{Si}$ NMR spectroscopy (see Figs. S67-S70 for 40, S72-S75 for 45, S77-S80 for $\mathbf{5 0}$ and S82-S85 for $\mathbf{5 5}$ in the SI). GC-MS data obtained dissolving $40\left(\mathrm{C}_{20} \mathrm{H}_{29} \mathrm{NO}_{2} \mathrm{Si}_{2}\right), 45\left(\mathrm{C}_{20} \mathrm{H}_{31} \mathrm{NSi}_{2}\right), \mathbf{5 0}\left(\mathrm{C}_{16} \mathrm{H}_{31} \mathrm{NSi}_{2}\right)$ and $\mathbf{5 5}$ $\left(\mathrm{C}_{16} \mathrm{H}_{31} \mathrm{NSi}_{2}\right)$ in $\mathrm{CH}_{2} \mathrm{Cl}_{2}$ show peaks at 371.3, 341.4, 293.1 and 293.3 Da, respectively, in agreement with the expected molecular formulae (see Figs. S71, S76, S81 and S86, respectively, in the SI). Comparing the results obtained in Table 3 with the previous ones summarized in Table 1 and 2, it can be concluded that also for benzyl and aliphatic amines excellent yields can be achieved for the double $\mathrm{A}^{3}$ coupling even at lower reaction times, although some dependency on the nature of the primary amine was noticed. Aliphatic amines [Table 3 (entries 1, 2, 3 and 4)] give best yields at shorter reaction times (1-2.2 h) compared to aromatic primary amines (Tables 1 and 2). It was also noted that benzyl amines require slightly shorter reaction times (1-2 h) than aliphatic amine.

In an attempt to isolate a gold(I)-aliphatic amine adduct that could shed light on the reaction mechanism and on the structure of the $\mathrm{Au}(\mathrm{I})$ intermediate, the reaction of a 1:3 mixture of gold(I) complex 1 and $n$-butylamine (50) in dry $\mathrm{CH}_{2} \mathrm{Cl}_{2}$ was performed at 50 ${ }^{\circ} \mathrm{C}$ for $24 \mathrm{~h}$ (Scheme 2). The resulting pale yellow solution was diluted with more $\mathrm{CH}_{2} \mathrm{Cl}_{2}$, followed by subsequent addition of $n$-hexane. After standing for one day at RT formation in $98 \%$ yield of colourless crystals of an air-stable complex $\mathbf{5 6}$ was observed. Complex 
56 was fully characterized by analytical and spectroscopic data (see the experimental Section and Table S2 and Figures S87-S92 in the SI] and assigned to cationic gold(I) $\left[\mathrm{LAu}\left(\mathrm{H}_{2} \mathrm{~N}-\left(\mathrm{CH}_{2}\right)_{3}-\mathrm{CH}_{3}\right)\right]\left[\mathrm{SbF}_{6}\right](\mathbf{5 6})$.

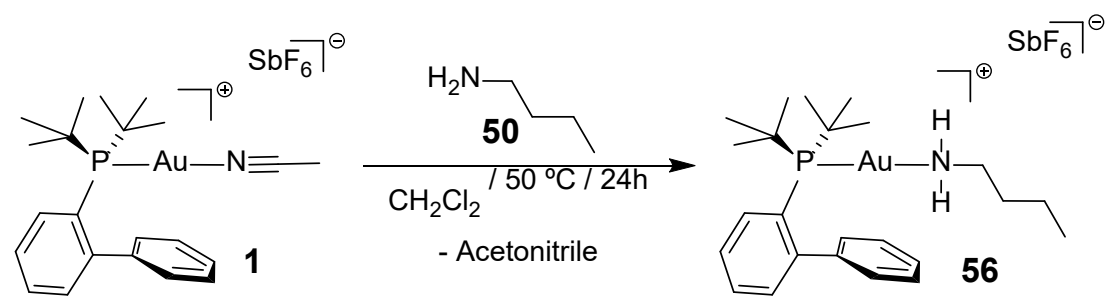

Scheme 2. Synthesis of the cationic gold (I) complex 56.

${ }^{1} \mathrm{H},{ }^{13} \mathrm{C}$, DEPT and ${ }^{31} \mathrm{P}$ NMR spectra in $\mathrm{CD}_{2} \mathrm{Cl}_{2}$ provided evidence that under the reaction conditions the starting cationic gold(I) complex $\mathbf{1}$ is completely converted to the corresponding cationic gold(I) complex 56, releasing the acetonitrile ligand (see Figures S87-S90 in the SI). Thus, ${ }^{31} \mathrm{P}$ NMR spectrum shows the appearance of a new peak at $\delta=$ 59.24 ppm attributable to complex 56 (see Figures S90 in the SI), while peak the corresponding to the original gold(I) complex 1 (57.49 ppm) disappeared.

ESI-MS of cationic $\left[\mathrm{LAu}\left(\mathrm{H}_{2} \mathrm{~N}-\left(\mathrm{CH}_{2}\right)_{3}-\mathrm{CH}_{3}\right)\right]\left[\mathrm{SbF}_{6}\right]$ (56) complex was measured after dissolving it in $\mathrm{CH}_{2} \mathrm{Cl}_{2}$. An intense positive MS peak at 568.3 Da (see Fig. S91 in the SI) attributable to the cationic $\left[\mathrm{C}_{24} \mathrm{H}_{38} \mathrm{AuF}_{6} \mathrm{NPSb}(\mathbf{5 6})-\mathrm{SbF}_{6}\right]^{+}$species was recorded. The peak exhibits an isotopic distribution that was in good agreement with the simulation for the molecular formula $\left[\mathrm{C}_{24} \mathrm{H}_{38} \mathrm{AuNP}\right.$ ] (see Fig. S91 in the SI). In addition, negative MS peaks at 234.7 and $236.6 \mathrm{Da}$ corresponding to the two ${ }^{121} \mathrm{Sb}$ and ${ }^{123} \mathrm{Sb}$ isotopes of [ $\left.\mathrm{SbF}_{6}\right]^{-}$ counter anion were found (See Fig. S91 in the SI).

The solid state structure of cationic gold(I) complex $\mathbf{5 6}$ was confirmed by single-crystal $\mathrm{X}$-ray diffraction. Ortep of this new cationic $\left[\mathrm{LAu}\left(\mathrm{H}_{2} \mathrm{~N}-\left(\mathrm{CH}_{2}\right)_{3}-\mathrm{CH}_{3}\right)\right]\left[\mathrm{SbF}_{6}\right]$ (56) complex is shown in Figure 2 (for X-ray data, ortep view and crystal packing details see Table S2 and Fig. S92 in the SI).

Selected bond lengths for Au1-N1, Au1-P1 and Au1-C7 $7_{i p s o}$ that is the closest carbon atom of the distal phenyl ring for complex 56 (Table S2 and Fig. S92 in the SI) are 2.117(9), 2.263(3) and $3.007 \AA$, respectively. These bond lengths are slightly longer than the 
previous cationic $\left[\mathrm{LAu}\left(\mathrm{H}_{2} \mathrm{~N}-\mathrm{Ph}\right.\right.$-vinyl $\left.\left.)\right)\right]\left[\mathrm{SbF}_{6}\right]$ (35) complex commented previously, indicating that $n$-butylamine (50) can be more easily exchanged from the coordination sphere of gold(I) compared to vinylaniline (30). Looser coordination of the amine to $\mathrm{Au}(\mathrm{I})$ should provide open coordination sites at which the catalytic reaction can occur more easily [see Table 2 (entry 6) and Table 3 (entry 5)].

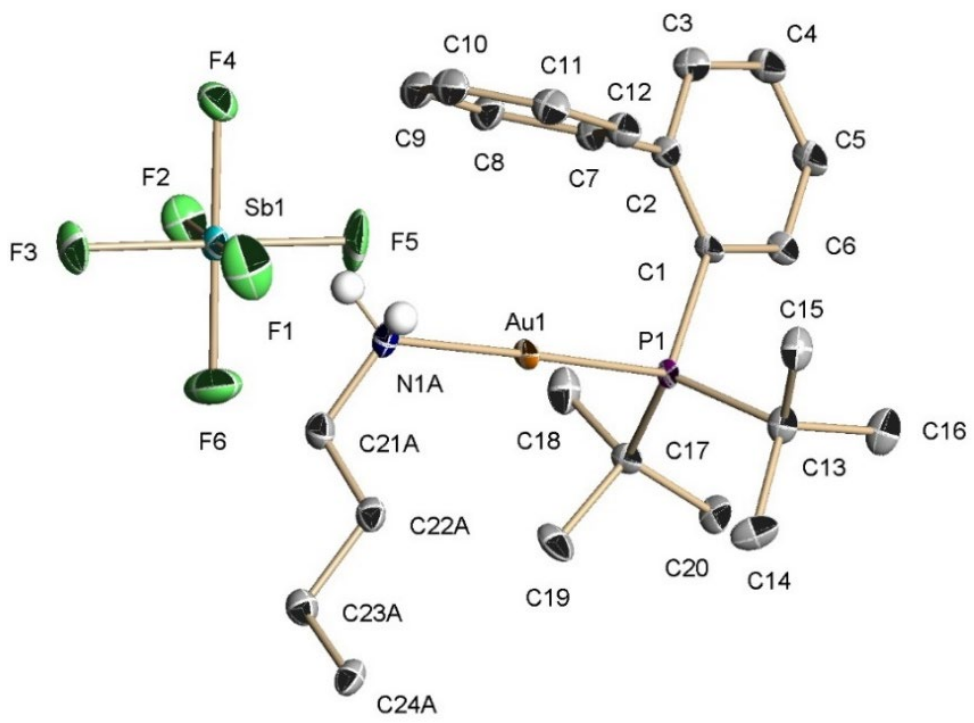

Figure 2. ORTEP of cationic gold (I) complex 56; hydrogen atoms bound to carbon atoms are omitted for clarity, and ellipsoids are given at the $30 \%$ probability level (a singlecrystal X-ray crystal structure analysis data and crystal packing details are given in Table S2 and Fig. S92 in the SI).

The catalytic activity of cationic $\left[\mathrm{LAu}\left(\mathrm{H}_{2} \mathrm{~N}-\left(\mathrm{CH}_{2}\right)_{3}-\mathrm{CH}_{3}\right)\right]\left[\mathrm{SbF}_{6}\right](\mathbf{5 6})$ complex was tested for the five-component double $\mathrm{A}^{3}$ coupling obtaining N,N-bis(3-(trimethylsilyl)prop-2yn-1-yl)butan-1-amine (55) in high yield and excellent selectivity [Table 3 (entry 5)], very similar to the results obtained when cationic $[\mathrm{LAu}(\mathrm{NCMe})]\left[\mathrm{SbF}_{6}\right]$ (1) complex catalyst was used [Table 3 (entry 4)].

Concerning the mechanism reaction, it is important to mention here the isolation and

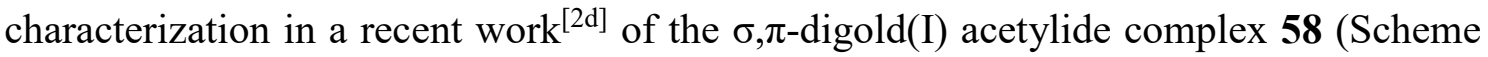
3) when stoichiometric amounts of cationic $[\mathrm{LAu}(\mathrm{NCMe})]\left[\mathrm{SbF}_{6}\right]$ (1) complex are reacted with TMS-acetylene (3) in dry $\mathrm{CH}_{2} \mathrm{Cl}_{2}$ at $40{ }^{\circ} \mathrm{C}$ for $24 \mathrm{~h}$. This digold complex 58 was assumed to be in equilibrium with the catalytically active cationic $\pi$-gold(I) acetylide complex 57. It should be mentioned at this point that similar equilibrium has been found 
in the literature, ${ }^{[8]}$ but with $\mathrm{PBu}_{3}^{\mathrm{t}}$ as ligand instead of bulky Buchwald-type biaryl phosphane (L).

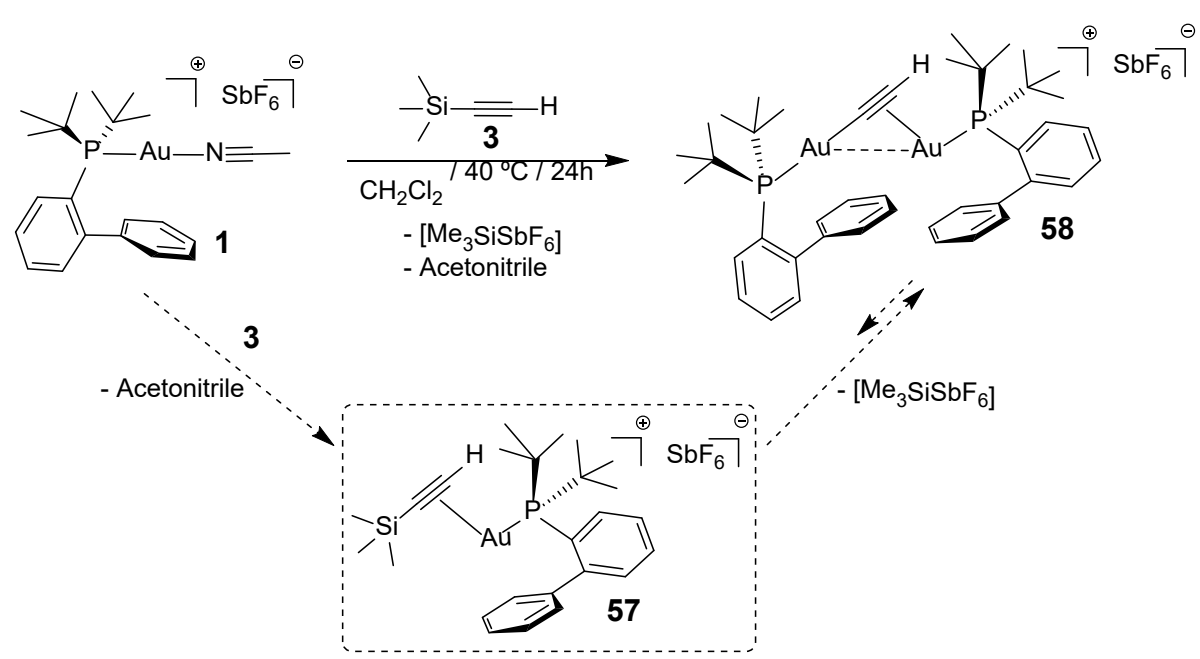

Scheme 3. Synthesis of the cationic gold (I) complex 58.

Normally the equilibrium is favorable to the formation of the digold(I) complex $\mathbf{5 8}$ (Scheme 3). Based on this precedent, it is proposed that also in this study of multicomponent coupling, gold(I) 57 should be involved as one of the key reaction intermediates (see below).

To gain further information, additional experiments were performed monitoring the evolution of the reaction mixture by ${ }^{1} \mathrm{H}$ and ${ }^{31} \mathrm{P}$ NMR spectroscopy, looking for signals supporting the intermediacy of gold(I) intermediates including amine $(\mathbf{9}, \mathbf{3 5}, \mathbf{5 6} \ldots .$.$) and$ acetylide (57 and 58) gold(I) complexes. In the first measurements, $15 \mathrm{~mol} \%$ of gold complex 1 was added to TMS-acetylene (3) at $\mathrm{RT}$ in $\mathrm{CD}_{2} \mathrm{Cl}_{2}$, whereby ${ }^{31} \mathrm{P} \mathrm{NMR}$ spectroscopy recorded at $5 \mathrm{~min}$ reaction time showed new peaks at $63.11(6 \%)$ and 62.46 (80\%) ppm attributable, respectively, to cationic $\pi$-gold(I) acetylide complex 57 and cationic $\sigma, \pi$-digold(I) acetylide complex 58, together with the peak corresponding to unreacted original complex 1 at 57.65 (14\%) ppm (see Fig. S93 in the SI). Also, ${ }^{1} \mathrm{H}$ NMR spectroscopy confirmed the coexistence of complexes 1, 57 and $\mathbf{5 8}$ (see Fig. S94 in the SI). Over the time (30 min) complex 1 completely disappeared, and exclusively gold(I) 57 (17\%) and digold(I) 58 (83\%) remained (see Fig. S95 in the SI). In a continuation of this study, 3,4-(methylenedioxy)benzylamine (36) (as model of primary amines) and 
formaldehyde (4) were added to the previous mixture, monitoring the changes again by NMR spectroscopy. After $2 \mathrm{~h}$ at RT, the mixture was analysed by ${ }^{31} \mathrm{P}$ NMR spectroscopy, which showed that besides remaining peaks of gold(I) 57 at 63.10 ( $4 \%$ ) and digold(I) 58 at $62.46(30 \%)$ ppm, new peaks appear at $62.80(8 \%), 62.00(53 \%)$ and $60.26(4 \%)$ ppm attributable, respectively, to cationic gold(I) complexes 60, 62 and 61 ppm (see Scheme 4 and Fig. S96 in the SI). Worth noting is that the peak at $58.46 \mathrm{ppm}$ in ${ }^{31} \mathrm{P}$ NMR spectroscopy corresponding to cationic gold(I) $\left[\mathrm{LAu}\left(\mathrm{H}_{2} \mathrm{~N}-\mathrm{Ph}-3,4\left(-\mathrm{O}-\mathrm{CH}_{2}-\mathrm{O}-\right)\right]\left[\mathrm{SbF}_{6}\right]\right.$ (59) is missing in this mixture, due presumably to the prompt reactivity of this intermediate in this stage. This proposal about the formation of a series of gold(I) complexes based on ${ }^{31} \mathrm{P}$ NMR spectroscopy was more firmly confirmed by HRESI-MS spectroscopic analysis of the reaction mixture at this point. The presence of positive MS peaks at $\mathrm{m} / \mathrm{z}$ values of 593.2051 (57), $646.2130(\mathbf{5 9})$ and 1288.4274 (62) was recorded (see Figs. S97, S98 and S99, respectively, in the SI). HRESI-MS fragmentation was also in complete accordance with the structure of gold(I) complexes 57, 59 and 62 (Figs. S97S99 in the SI), confirming without ambiguity the composition and formation of these gold(I) complexes as intermediates. Note also that assignment of ${ }^{31} \mathrm{P}$ NMR signals for complex 59 was confirmed by performing the direct synthesis of gold(I) amine adduct 59 in $97 \%$ yield, by reacting cationic $[\mathrm{LAu}(\mathrm{NCMe})]\left[\mathrm{SbF}_{6}\right]$ (1) and 3,4(methylenedioxy)benzylamine (36) and then characterizing the adduct by analytical and spectroscopic data (see the ES and Figs. S97-S100 in the SI).

Based on all these experimental data and in agreement with related precedents for single and double $\mathrm{A}^{3}$ coupling of secondary amines, ${ }^{[1 \mathrm{i}, 2 \mathrm{~d}]}$ a plausible reaction mechanism for this one pot, double $\mathrm{A}^{3}$ - coupling can be proposed (Scheme 4). The main feature of this mechanism is the coordination of $\mathrm{Au}(\mathrm{I})$ precatalyst $\mathbf{1}$ with the ethynyl group leading to the cationic $\pi$-gold(I) acetylide complex (57) in equilibrium with the $\sigma, \pi$-digold(I) acetylide complex (58) activating the $\mathrm{C} \equiv \mathrm{C}$ triple bond as catalytic intermediates. Also, cationic gold(I) amine adducts $(9,35,56,59 \ldots)$ have to formed at early stage of reaction by exchange of acetonitrile by primary amines (see Scheme 4). The condensation between formaldehyde and primary amines take place to form the imines as reaction intermediates $(5,11,16 \ldots)$ (see Scheme 4). The presumed $\pi$-gold(I) complexes intermediates 60 and 61 involved in the catalytic mechanism, will undergo fast N-ligand exchange to form the second $(6,12,17 \ldots)$ and third $(7,13,18 \ldots)$ organic compounds intermediates with regeneration of the gold(I) adducts catalysts $(\mathbf{9}, \mathbf{3 5}, \mathbf{5 6}, \mathbf{5 9} \ldots)$ (see Scheme 4$)$. In the last 
step, dipropargylamines $(\mathbf{8}, \mathbf{1 4}, \mathbf{1 9} \ldots)$ would be formed as final products by exchange from the coordination sphere of di-gold(I) intermediate catalyst 62, with free amine present in the reaction medium, and regeneration of the $[\mathrm{Au}(\mathrm{L})(\mathrm{amine})]\left[\mathrm{SbF}_{6}\right](\mathbf{9}, \mathbf{3 5}, \mathbf{5 6}$, 59...) catalyst complex intermediates that would start over a subsequent cycle of this reaction.

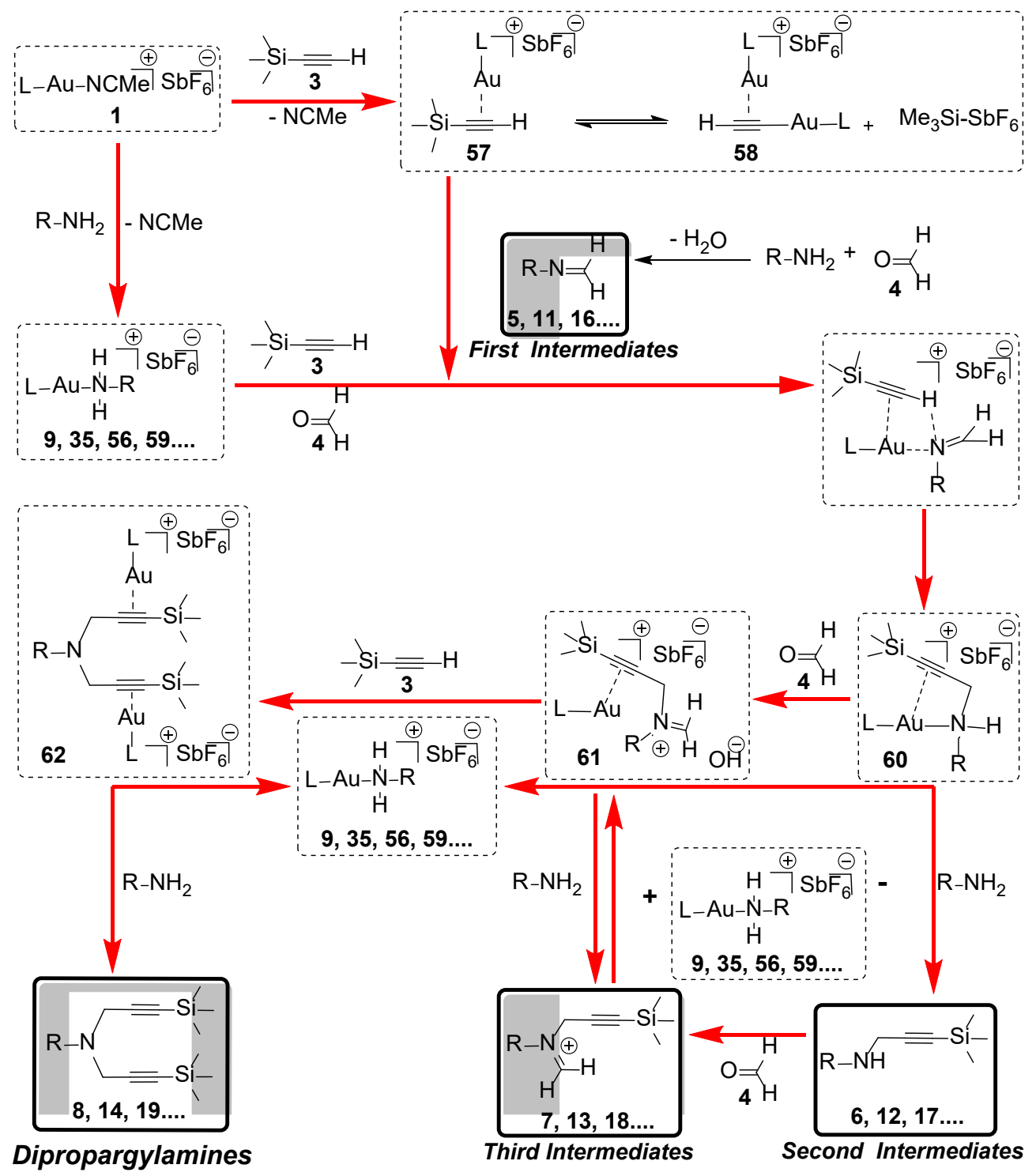

Scheme 4. Plausible mechanism for one pot, double $A^{3}$ - coupling of primary amines, fromaldehyde and trimethylsilylacetylene to form dipropargylamines using cationic gold(I) complex 1 as precatalyst in $\mathrm{CH}_{2} \mathrm{Cl}_{2}$. Note: Continuous and dashed squares correspond to organic compounds and gold(I) intermediate, respectively. 
To further exploit the excellent results of the double $\mathrm{A}^{3}$ coupling, a route to obtain a new family of dipropargylamines having terminal alkynes by desilylation of formed disilylpropargyl amines products $(\mathbf{8}, \mathbf{1 4}, \mathbf{1 9}, \mathbf{2 4} \ldots)$ was developed. Thus, when ethanol $(0.5$ $\mathrm{ml}$ ) is added over the reaction mixture of dipropargylamines $\mathbf{4 0}$ and $\mathbf{5 5}$ [Table 3 (entries 1 and 4)] and the mixtures stirred for $1 \mathrm{~h}$ at $50^{\circ} \mathrm{C}$ before adding aqueous $\mathrm{NaOH}$ solution $(0.5 \mathrm{ml}, 0.5 \mathrm{M})$ over each reaction, stirring the resulting biphasic mixture for additional $23 \mathrm{~h}$ [Table 4, scheme (Top)], then, appearance of mono-deprotected silyl compounds 63, $\mathbf{6 5}$ and formation in higher yields of the double-deprotected silyl bis propargylamines $\mathbf{6 4}$, 66 [Table 4, Scheme (Top), entries 1 and 2], was observed. Both mono-deprotected silyl intermediates 63 and 65 were characterized during the course of the corresponding reactions, by GC-MS, by recording peaks at 300.1 and $221.2 \mathrm{Da}$, respectively, in agreement with the expected molecular formulae $63\left(\mathrm{C}_{17} \mathrm{H}_{21} \mathrm{NO}_{2} \mathrm{Si}\right)$ and $\mathbf{6 5}\left(\mathrm{C}_{13} \mathrm{H}_{23} \mathrm{NSi}\right)$ ( S104 and S105 in the SI).

The fully deprotected dipropargylamines 64 and 66 were isolated in excellent yields [Table 4, entries 1 and 2] and characterized by ${ }^{1} \mathrm{H},{ }^{13} \mathrm{C}$ and DEPT NMR spectroscopy (see Figs. S106-S108 for 64 and S110-S112 for 66 in the SI). Also, GC-MS data obtained dissolving $64\left(\mathrm{C}_{14} \mathrm{H}_{13} \mathrm{NO}_{2}\right)$ and $66\left(\mathrm{C}_{10} \mathrm{H}_{15} \mathrm{~N}\right)$ in $\mathrm{CH}_{2} \mathrm{Cl}_{2}$ showed peaks at 227.1 and 149.1 $\mathrm{Da}$, respectively, in agreement with the expected molecular formulae (see Figs. S109 and S113, respectively, in the SI).

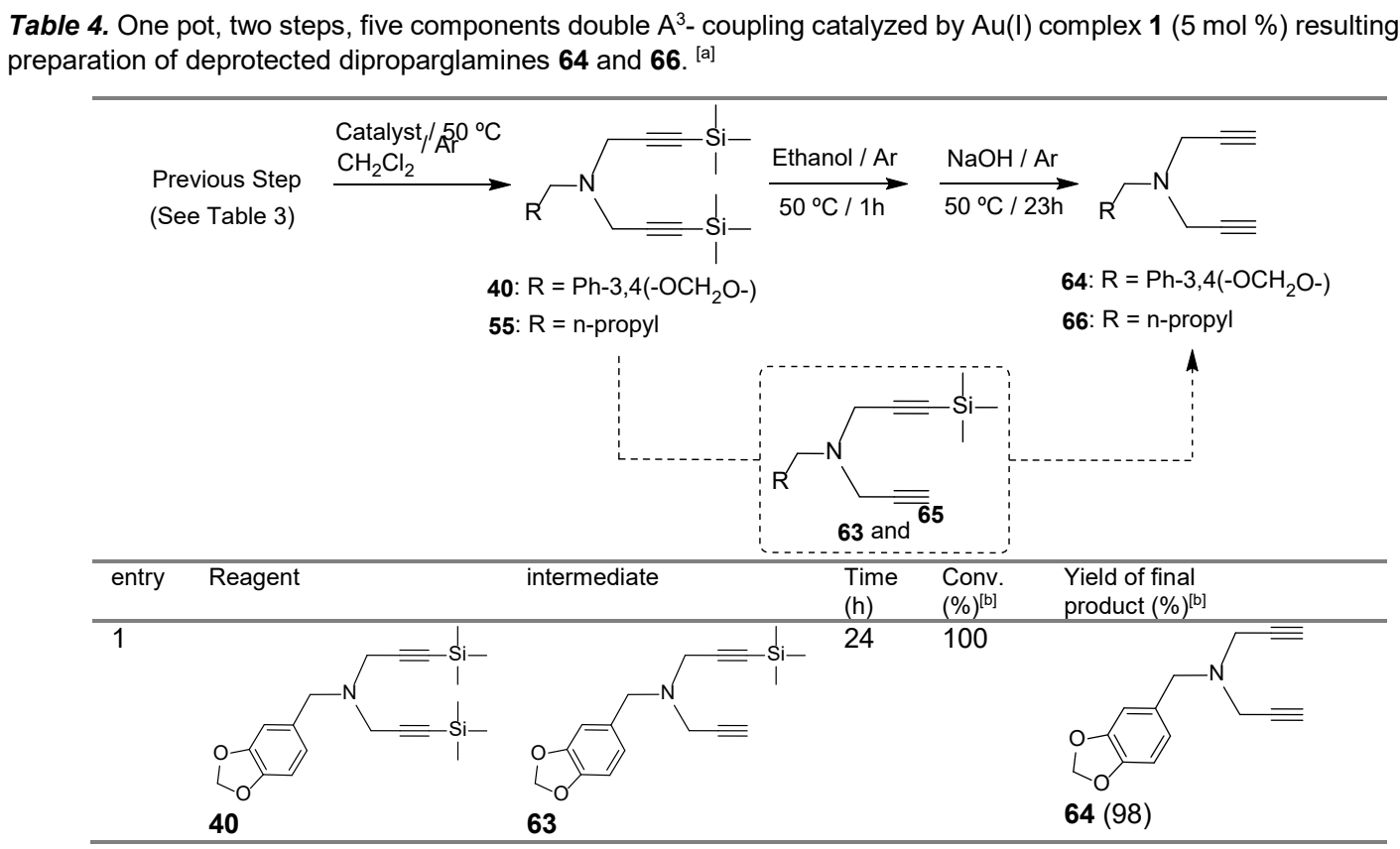




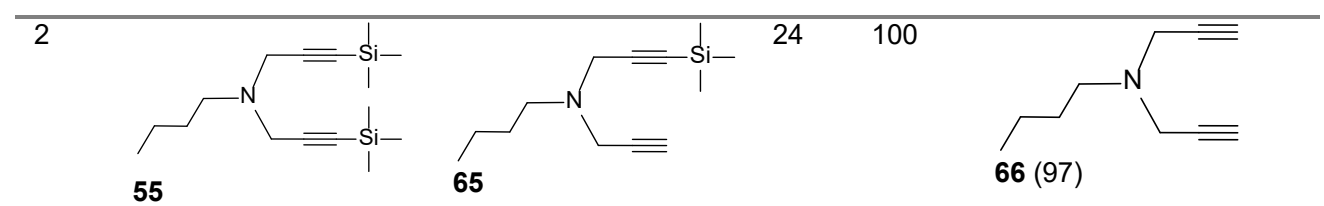

[a] Reactions were carried out using $0.25 \mathrm{mmol}$ of amine, 0.7 of TMS-acetylene and $1 \mathrm{mmol}$ of aqueous formaldehyde and $1.5 \mathrm{ml}$ of $\mathrm{CH}_{2} \mathrm{Cl}_{2}$ for the double coupling step (Table 3), followed by consecutive addition of ethanol $(0.5 \mathrm{ml})$ and aqueous $\mathrm{NaOH}(0.5 \mathrm{ml}, 0.5 \mathrm{M})$, in the second step. [b] Conv. of dipropargylamines 40,55 and yield of double-deprotected diproparglamines 64, 66 (\%) were determined by ${ }^{1} \mathrm{H}$ NMR spectroscopy and GC of the crude reaction mixture.

${ }^{1} \mathrm{H},{ }^{13} \mathrm{C}$ and DEPT NMR spectra in $\mathrm{CD}_{2} \mathrm{Cl}_{2}$ provided evidence that under the reaction conditions the starting disilylated dipropargylamines $\mathbf{4 0}$ and $\mathbf{5 5}$ are completely converted to the corresponding dipropargylamines compounds 64 and 66 , respectively, having double terminal alkynes by release of the silyl moieties (see Figures S106-S108 for 64 and S110-S1 12 for 65 in the SI). Thus, ${ }^{1} \mathrm{H}$ NMR spectra of 64 and 66 show, respectively, a nice coupling through the $\mathrm{C} \equiv \mathrm{C}$ bond, between the $\mathrm{CH}_{2}$ groups and the terminal $\mathrm{CH}$ moieties of ethynyl $(\mathrm{C} \equiv \mathrm{CH})$ appearing, respectively, at $\delta=3.33$ (doublet) and $2.26 \mathrm{ppm}$ (triplet), with ${ }^{3} J=2.35 \mathrm{~Hz}$ as coupling constant for 64 , and at $\delta=3.35$ (doublet) and 2.19 ppm (triplet), with ${ }^{3} J=2.38 \mathrm{~Hz}$ for $\mathbf{6 6}$ (see Figures S106 for $\mathbf{6 4}$ and S110 for $\mathbf{6 5}$ in the SI).

The temporal evolution of the formation of $\mathbf{6 3}$ as intermediate and $\mathbf{6 4}$ as final product in the double triple bond deprotection in the diporparglamine 40 (Table 4, entry 1) previously synthesized in one pot (Table 4, entry 1) using Au(I) complex $\mathbf{1}$ as catalyst is shown in Figure 3. As it can be seen in this Figure, the percentage of $\mathbf{6 3}$ arising from the deprotection of only one triple bond reaches a maximum at $3 \mathrm{~h}$ and, then, it decreases, appearing this compound as primary and unstable intermediate that continues reacting. In contrast, formation of compound $\mathbf{6 4}$ is observed after an induction period, appering this compound as secondary but stable reaction product reaching good yields (over $98 \%$ ) and high selectivity at long reaction times. The temporal evolution of the formation of $\mathbf{6 6}$ (Table 4, entry 2) as final product follows exactly the same kinetics as the one previously commented for the case of compound 64. 


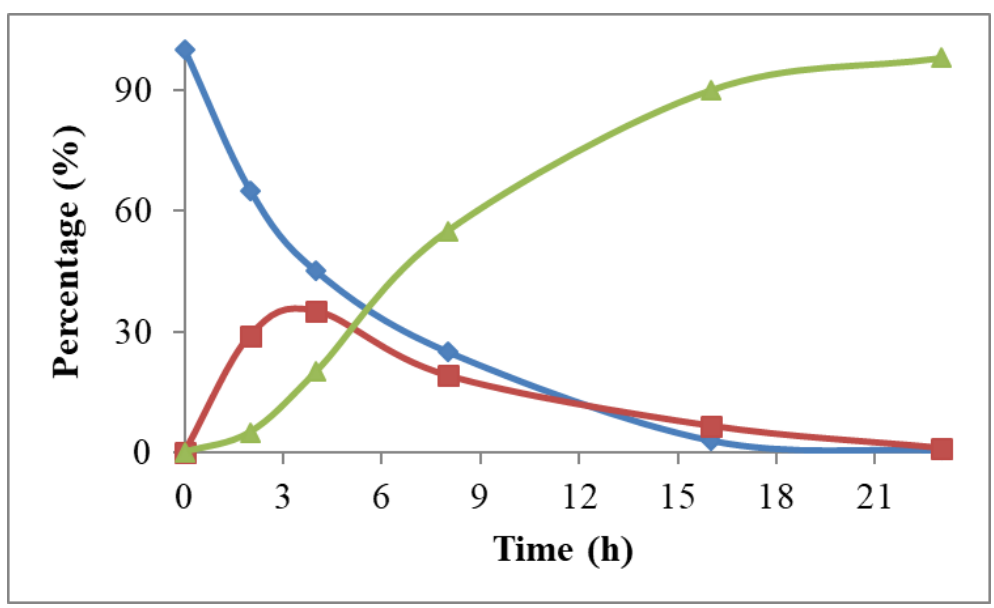

Figure 3. Time-conversion plot for the reaction of dipropargylamine $\mathbf{4 0}$ in ethanol and aqueous $\mathrm{NaOH}$ in the presence of cationic $\mathrm{Au}(\mathrm{I})$ complex 1. $(\diamond)$ : disappearance of dipropargylamine $40 ;(\square)$ : formation and disappearance of mono-deprotected dipropargylamine 63 and $(\Delta)$ : yield of double-deprotected dipropargylamine 64 .

Evidence in favour of the implication of other new gold(I) intermediates in this deprotection of silyl groups was obtained by performing an additional experiment of formation compound 64 (Table 4, entry 1), monitoring the reaction mixture at $6 \mathrm{~h}$ by HRESI-MS spectroscopy (see Figure S114 in the SI). It was observed that, besides organic compounds 40,63 and 64 as reagent, intermediate and final product, respectively (see Figure S114 in the SI), three new signals attributable to the corresponding gold(I) complexes appeared with positive MS peaks at $\mathrm{m} / \mathrm{z}$ values of 794.2849, 721,2860 and 512,1768 Da (see Scheme 5). These peaks should correspond according to HRESI-MS data, to the cationic gold(I) complexes $\left[\mathrm{C}_{37} \mathrm{H}_{48} \mathrm{AuF}_{6} \mathrm{NO}_{2} \mathrm{PSb} \text { (67) - } \mathrm{SbF}_{6}^{-}\right]^{+}$, $\left[\mathrm{C}_{34} \mathrm{H}_{40} \mathrm{AuF}_{6} \mathrm{NO}_{2} \mathrm{PSb}(\mathbf{6 8})-\mathrm{SbF}_{6}\right]^{+}$as high active intermediates and to the neutral gold(I) hydroxide complex $\mathrm{C}_{20} \mathrm{H}_{28} \mathrm{AuOP}$ (69) as the less active catalyst form (see Figure $\mathrm{S} 114$ in the SI), respectively. The measured isotopic distributions for these three gold(I) complexes are in good agreement with the simulated isotopic distributions for the molecular formulae $\left[\mathrm{C}_{37} \mathrm{H}_{48} \mathrm{AuF}_{6} \mathrm{NO}_{2} \mathrm{PSb}\right]^{+},\left[\mathrm{C}_{34} \mathrm{H}_{40} \mathrm{AuF}_{6} \mathrm{NO}_{2} \mathrm{PSb}\right]^{+}$and $\mathrm{C}_{20} \mathrm{H}_{28} \mathrm{AuOP}$ (see Figures S115-S117 for 67, 68 and S118 for 69 in the SI). The coincidence between the simulated and experimental isotopic distribution together with the high resolution mass of the peaks lend strong support to the corresponding molecular formula and, therefore, to the existence of the proposed gold(I) complex intermediates. It should be mentioned that the neutral LAu(I)-hydroxide complex 69 has been published previously ${ }^{[9]}$ as a new class of gold complex exhibiting strongly basicity. 
According of all these experimentally data and observations, a reasonable reaction mechanism for the formation of dipropargylamines 64 and 66 having double-deprotected terminal alkynes is shown in Scheme 5.

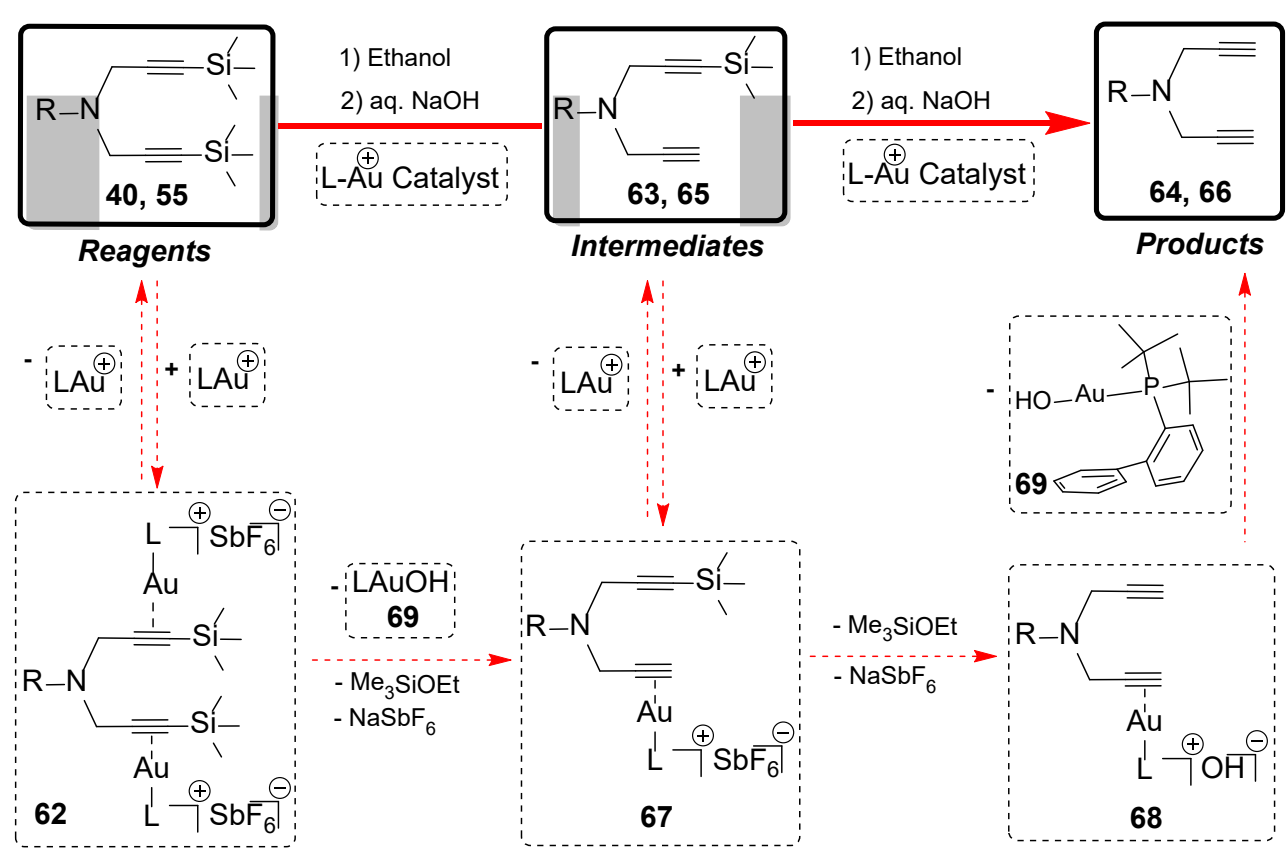

Scheme 5. Plausible reaction mechanism for the formation of double-deprotected dipropargylamines 64 and 66 after addition of ethanol and $\mathrm{NaOH}$ over the reaction crude of dipropargylamines 40 and 55. Continuous line and dashed squares indicate the evolution of organic compounds and gold(I) intermediates.

In summary, a five-component coupling of primary amines (aliphatic and aromatic), formaldehyde and trimethylsilylacetylene catalysed by a bulky $\mathrm{Au}(\mathrm{I})$ complex that operates in excellent yields under mild conditions using $\mathrm{CH}_{2} \mathrm{Cl}_{2}$ as solvent has been reported. In addition, double deprotection of the TMS groups of the coupling products makes possible subsequently, isolation of high added value dipropargylamines having two terminal alkynes. The organic reaction intermediates and products have been characterized spectroscopically and in some cases also by single-crystal X-ray diffraction. The catalytic cycle including gold(I) adducts has also been studied. Cationic aminegold(I)-L complexes were isolated and characterized by means of structural and spectroscopic proprieties, and their role in the reactions mechanism supported by control experiments. Also the role of cationic $\pi$-gold(I) acetylide and cationic $\sigma, \pi$-digold(I) acetylide complexes, previously proposed as key intermediates to activate the $\mathrm{C} \equiv \mathrm{C}$ triple 
bonds, has been confirmed by control NMR and HRESI-MS measurements. Overall the present results show the wide scope and versatility of double $\mathrm{A}^{3}$-coupling of primary amines promoted by $\mathrm{Au}(\mathrm{I})$ complexes with Buchwald ligand to obtain a wide range of structurally diverse propargylamines.

[1] aV. A. Peshkov, O. P. Pereshivko, E. V. Van der Eycken, Chem. Soc. Rev. 2012, 41, 37903807; bW.-J. Yoo, L. Zhao, C.-J. Li, Aldrichimica Acta 2011, 44, 43-51; cL. Zani, C. Bolm, Chem. Commun. (Cambridge, U. K.) 2006, 4263-4275; dC. Wei, C.-J. Li, J. Am. Chem. Soc. 2003, 125, 9584-9585; eS. Shi, T. Wang, V. Weingand, M. Rudolph, A. S. K. Hashmi, Angew. Chem., Int. Ed. 2014, 53, 1148-1151; fC. Wei, Z. Li, C.-J. Li, Synlett 2004, 14721483; gJ. Li, M. Rudolph, F. Rominger, J. Xie, A. S. K. Hashmi, Adv. Synth. Catal. 2016, 358, 207-211; hA. Grirrane, E. Alvarez, H. Garcia, A. Corma, Chem. - Eur. J. 2016, 22, 340354; iA. Grirrane, E. Alvarez, H. Garcia, A. Corma, Chem. - Eur. J. 2014, 20, 14317-14328; jA. Grirrane, E. Alvarez, H. Garcia, A. Corma, Angew. Chem., Int. Ed. 2014, 53, 7253-7258; kC.-J. Li, C. Wei, Chem. Commun. (Cambridge, U. K.) 2002, 268-269; IH. Cheng, J. Wen, C. Bolm, Chem. - Eur. J. 2017, 23, 12100-12103.

[2] aZ. Lin, D. Yu, Y. N. Sum, Y. Zhang, ChemSusChem 2012, 5, 625-628; bH. Feng, D. S. Ermolat'ev, G. Song, E. V. Van der Eycken, J. Org. Chem. 2012, 77, 5149-5154; cN. Uhlig, C.-J. Li, Org. Lett. 2012, 14, 3000-3003; dA. Grirrane, E. Alvarez, H. Garcia, A. Corma, Chem. - Eur. J. 2017, 23, 2792-2801.

[3] aS. Sakaguchi, T. Kubo, Y. Ishii, Angew. Chem., Int. Ed. 2001, 40, 2534-2536; bS. Sakaguchi, T. Mizuta, M. Furuwan, T. Kubo, Y. Ishii, Chem. Commun. (Cambridge, U. K.) 2004, 1638-1639; cC. Wei, C.-J. Li, J. Am. Chem. Soc. 2002, 124, 5638-5639; dL. Zani, S. Alesi, P. G. Cozzi, C. Bolm, J. Org. Chem. 2006, 71, 1558-1562; eE. R. Bonfield, C.-J. Li, Adv. Synth. Catal. 2008, 350, 370-374.

[4] E. R. Bonfield, C.-J. Li, Org. Biomol. Chem. 2007, 5, 435-437.

[5] N. Sharma, U. K. Sharma, N. M. Mishra, E. V. Van der Eycken, Adv. Synth. Catal. 2014, 356, 1029-1037.

[6] aA. Stephen, K. Hashmi, G. J. Hutchings, Angew. Chem., Int. Ed. 2006, 45, 7896-7936; bA. Arcadi, Chem. Rev. (Washington, DC, U. S.) 2008, 108, 3266-3325; cS. Diez-Gonzalez, N. Marion, S. P. Nolan, Chem. Rev. (Washington, DC, U. S.) 2009, 109, 3612-3676; dD. J. Gorin, B. D. Sherry, F. D. Toste, Chem. Rev. (Washington, DC, U. S.) 2008, 108, 33513378; eA. Fuerstner, P. W. Davies, Angew. Chem., Int. Ed. 2007, 46, 3410-3449; fD. Pflaesterer, A. S. K. Hashmi, Chem. Soc. Rev. 2016, 45, 1331-1367; gL. Prati, A. Villa, Acc. Chem. Res. 2014, 47, 855-863.

[7] A. Grirrane, H. Garcia, A. Corma, E. Alvarez, Chem. - Eur. J. 2013, 19, 12239-12244.

[8] T. N. Hooper, M. Green, C. A. Russell, Chem. Commun. (Cambridge, U. K.) 2010, 46, 23132315.

[9] A. Zhdanko, M. Stroebele, M. E. Maier, Chem. - Eur. J. 2012, 18, 14732-14744, S14732/14731-S14732/14102. 